Session 3413

\title{
An Improved Distance Learning Environment for the Material and Energy Balances Course
}

\author{
David L. Silverstein \\ G. T. Lineberry \\ University of Kentucky
}

\begin{abstract}
The Kentucky Council on Post-Secondary Education has mandated goals of substantially increased enrollments in Engineering for Kentucky state-funded institutions over the next decade. As part of the process designed to meet this goal, the University of Kentucky has collaborated with other state institutions providing (or soon to provide) engineering education (University of Louisville, Murray State University, and Western Kentucky University), along with the Kentucky Community and Technical College System (KCTCS) and selected independent colleges (e.g., Kentucky Wesleyan) to develop a collection of offerings of preengineering courses at community colleges across the state. The courses have been selected to allow students graduating from two-year programs to then enter four-year programs and complete an engineering degree within two additional years.
\end{abstract}

As part of this project, the specific needs of certain courses have been considered in the redesign of distance-learning classrooms in order to provide an effective instructional environment. One of the courses to be offered is "Process Principles," the sophomore course in material and energy balances common to virtually every chemical engineering program. An effective learning experience in this course is required for a student to be well prepared to continue in a chemical engineering program upon matriculation into a four-year institution. The evolutionary upgrade to the current compressed video distance-learning network in place across the Commonwealth is described. A long-term plan to incorporate pedagogical elements, such as collaborative learning, critical to an effective Process Principles course, is also proposed.

\section{Introduction}

Distance learning classrooms have evolved in a manner which often seems driven by technology rather than the learning process. Early distance offerings were correspondence courses, driven by paper based resources. Later offerings were by videotape, emphasizing a reproduction of the visual classroom experience. More modern implementations of synchronous distance courses involve used of videoconferencing technology, utilizing land-based phone lines, satellite 
transmission, or internet-based methods. Many of these courses are supplemented beyond textual resources using web-based hypermedia resources.

With the range of distance courses offered by universities today, it is clear that a one-size-fits-all approach to designing a distance classroom cannot accommodate courses in all disciplines effectively. The needs of a course in history, for example, are much different than a course on engineering statics. Some elements are common - students seem to like seeing a person giving a lecture - and they like visual examples. Group discussion is also important in most courses. Many current classrooms, however, do not allow for group efforts, and those that do usually do not allow more than text or voice collaboration.

The recent call from the Kentucky Council on Post-Secondary Education (CPE) to increase enrollments in engineering in Kentucky's state-funded institutions has led to an opportunity to focus a redesign of distance learning classrooms. As part of the process designed to meet this goal, the University of Kentucky (UK) has collaborated with other state institutions providing (or soon to provide) engineering education (University of Louisville, Murray State University, and Western Kentucky University), along with the Kentucky Community and Technical College System (KCTCS) and selected independent colleges to develop a collection of offerings of preengineering courses at community colleges across the state. The courses have been selected to allow students emerging from two-year programs to then enter four-year programs (often with an A.S. credential) and complete an engineering degree within two additional years.

The courses covered by this initiative would not be offered at the receiving schools due to low demand and the corresponding lack of resources to offer these courses, which range from calculus and physics to statics, thermodynamics, and the chemical engineering materials and energy balance course (hereafter referred to as "Process Principles"). Since the intent of these offerings is to prepare a student for on-schedule graduation in an engineering program, the quality of these offerings must be uncompromised to ensure a solid engineering foundation for these students. In an era of rapidly rising cost of higher education, the likelihood of on-time graduation is becoming a criterion in one's decision on major.

\section{Background}

The need for collaborative work to maximize student learning is clear, with research specific to the Process Principles course, indicating a strong benefit to active and group work activities ${ }^{1}$. This course is challenging to most students regardless of teaching approach but must be mastered in order to successfully proceed through the chemical engineering curriculum. A distance offering adds to the difficulty of the course due to the unavoidable detachment from the instructor and classmates that is inherent in an off-site course. Asynchronous communication methods for discussion, while well suited for certain topics and other courses, are not well suited to developing the problem-solving skills completion of this course requires. 
The distance learning technology in use in Kentucky is centered around a statewide network of "Interactive TeleVision" sites (ITV). ITV sites are located at all community colleges in the Kentucky Community and Technical College System (KCTCS), Lexington Community College, the University of Kentucky, and other sites around the state. These sites use dedicated T1 lines to transmit multipoint constant bit rate low-level MPEG-2 compressed video and audio. This video format is a low quality version of the technology used for DVD video. Various organizations and institutions use these classrooms to offer classes, seminars, and conferences across Kentucky.

With the establishment of the University of Kentucky College of Engineering Extended Campus Programs in Paducah ${ }^{2,3}$ (referred to as the UK COE Paducah Programs), undergraduate and graduate engineering courses were for the first time offered via ITV on a regular basis. The Paducah Programs are 4-year B.S. degree programs offered in chemical and mechanical engineering on site in Paducah, in cooperation with Murray State University (MuSU) and Paducah Community College (PadCC). Eight full-time UK faculty are assigned to the Paducah Program. Almost all classes are offered live in Paducah, with more classes offered via ITV from Paducah to Lexington (UK main campus) than from Lexington to Paducah.

Offering engineering classes via ITV required significant modification to courses previously offered on a "face-to-face" only basis ( $\mathrm{f} 2 \mathrm{f}$ ). Some of the considerations are common to any distance course - management of homework, exams, office hours, etc. Most of these requirements were handled with on-site teaching assistants, with electronic document handling, and with desktop videoconferencing. Others issues relate to the specific arrangement of the distance classroom itself, as detailed below.

Figure 1 is a photo of the area from which the instructor controls the flow of the class. The instructor must remain within this "cage" during the course in order to produce the class. $\mathrm{He} / \mathrm{She}$ is responsible for determining which singular video feed is available to students at remote sites. The choices of inputs from the instructor's station include a document camera, a $\mathrm{PC}$ with scan converter, and a video camera trained on the instructor, as shown in Figure 1. 


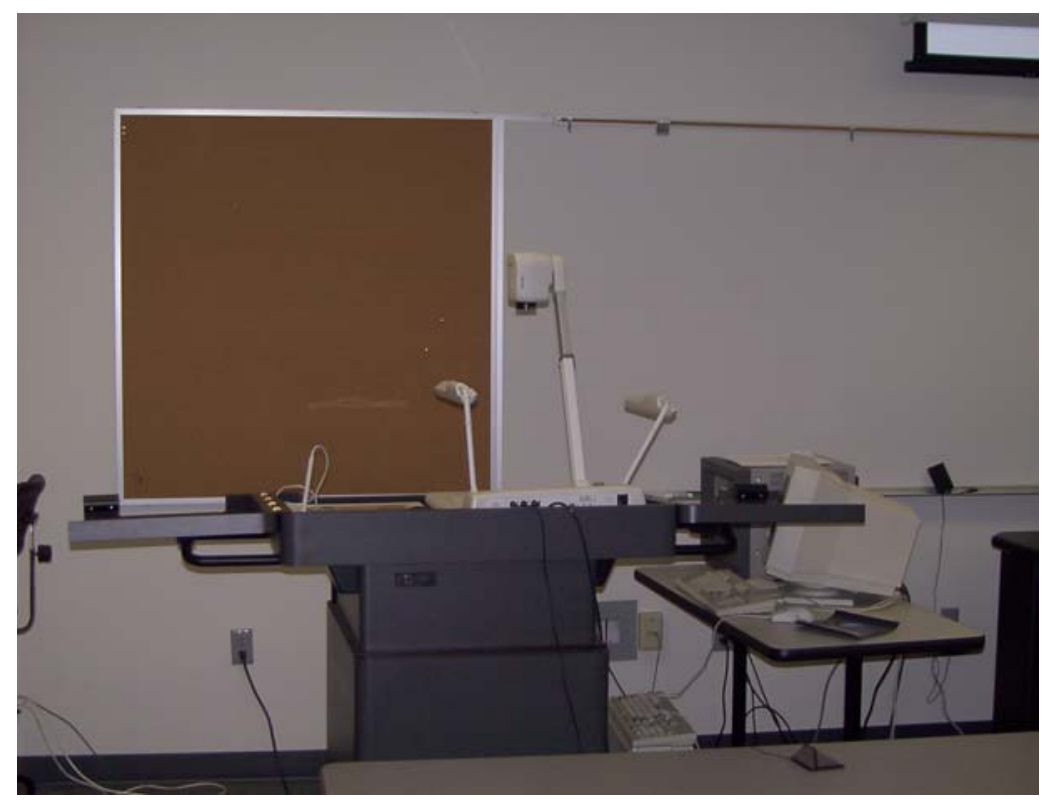

Figure 1. Instructor Cage

During a class, the instructor is responsible for determining what the remote student sees in the classroom monitors. So, in addition to keeping up with lecture notes, keeping focused on the course content, and tracking student response, the instructor must also work with the control panel illustrated at the bottom of Figure 2.

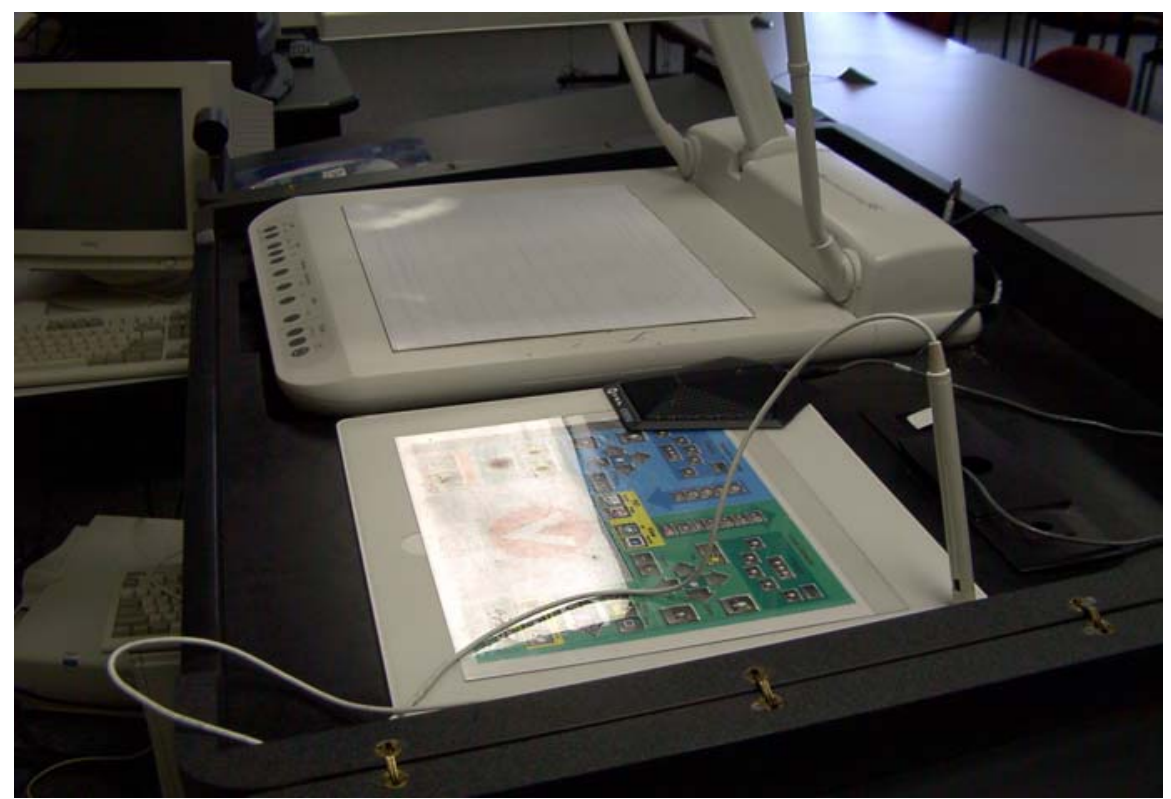

Figure 2. Producer or Professor? The device at the bottom of the image is the control panel, and the document camera is at the top of the image. 
At the top of that same figure is the document camera. Instead of a whiteboard and overhead projector, all images must be placed under the document camera and reduced to the resolution of a compressed TV broadcast. Consequently, writing must be large to be readable, which does not allow much information to fit on a single "page." Most instructors in the Paducah program prepare all "slides" ahead of time due to the restrictions of the document camera, whereas in a f $2 \mathrm{f}$ course, the whiteboard supplemented by slides would be the normal mode of instruction.

The instructor has a view of the remote site at a distance from the "cage" (Figure 3). A large television displays an image of the remote site at a wide view. It is virtually impossible to "read" student response to a lecture due to the size of the image. The television is considered immobile due to the camera mounted on top of it.

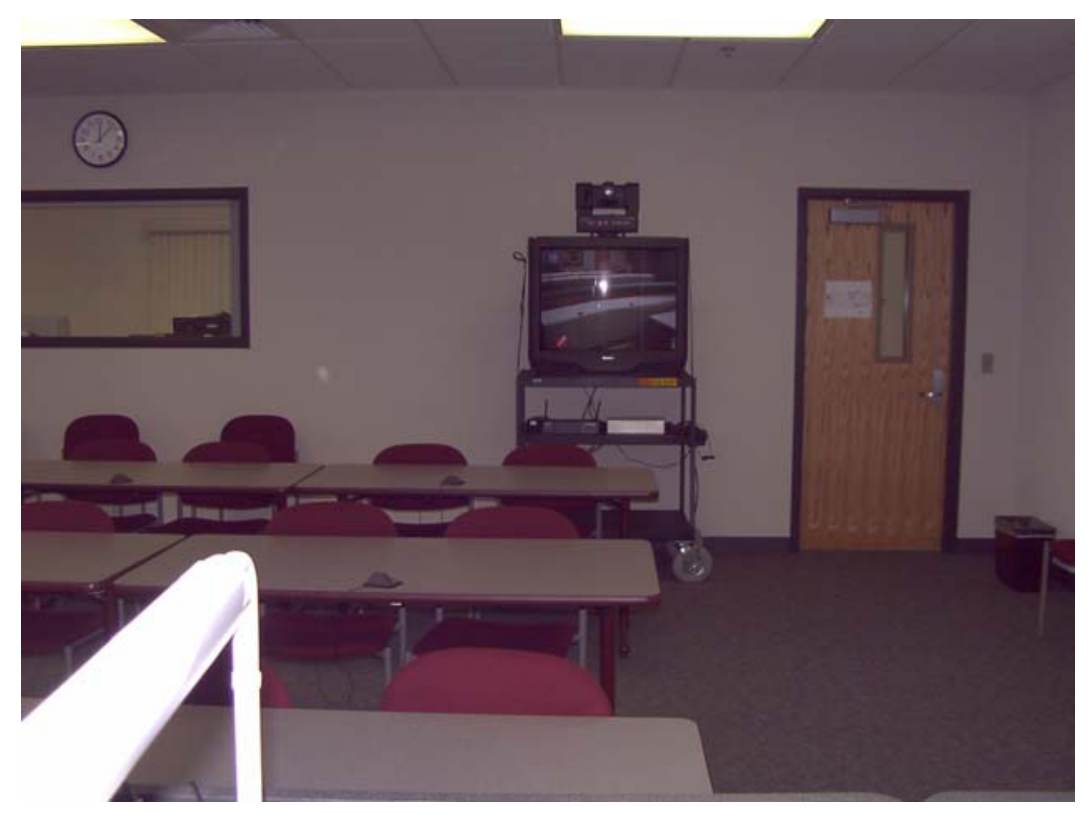

Figure 3. The Pigeon's View. The instructor is effectively trapped at this location the entire class period.

The students have similar issues when viewing the transmitted lecture. As shown in Figure 4, two monitors at the front of the classroom display the transmitting image of themselves, which the instructor will see, and the image from the instructor (this is also displayed at additional locations in larger classrooms). The instructor image, again, can be only from one input, so either the live instructor, document camera image, or other source material is displayed. 


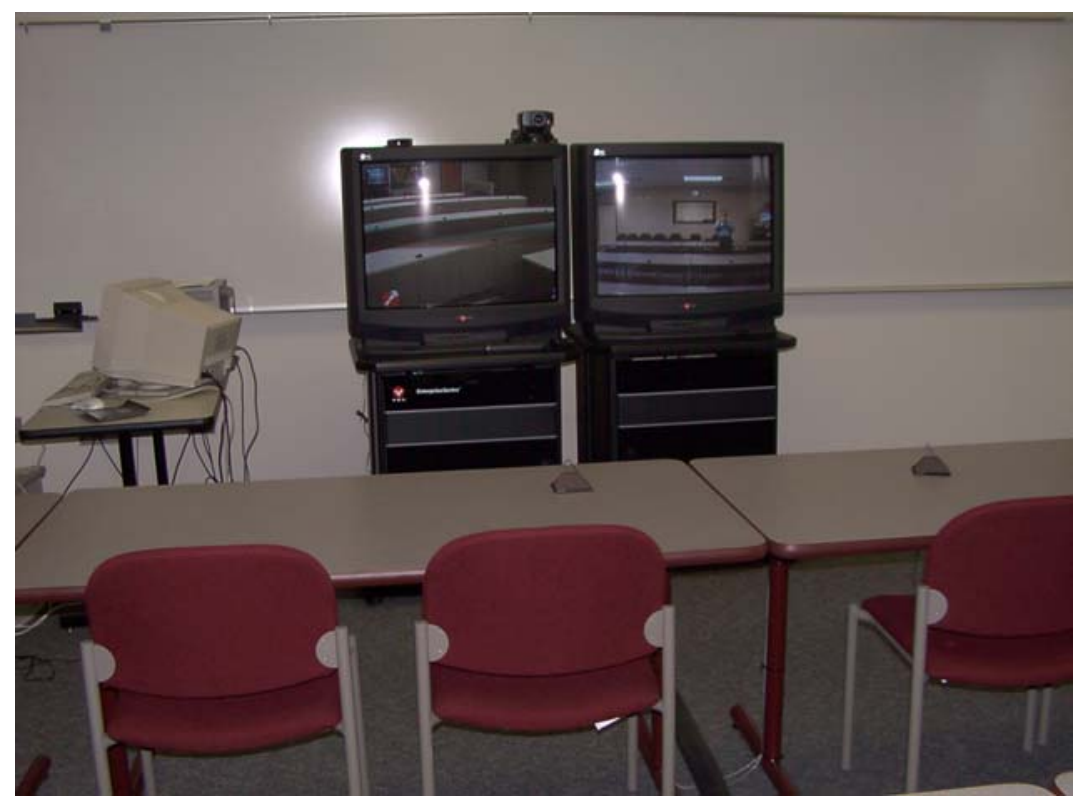

Figure 4. Students at a Distance. Note the size of the image of the photographer in the right monitor.

In Figure 4 one also may note the microphones placed at each student table. There is some capability for two-way interaction between students and the instructor, but with background noise, inefficient automatic voice input switching, feedback concerns, and frequent student reluctance to speak during class, this function is underutilized. When more than two sites are involved in a transmission, the context switches make the system difficult to use in an interactive mode.

In the discussion to this point, it should be clear that the currently implemented "Interactive TeleVision" is not truly interactive. Furthermore, students routinely indicate in surveys that they avoid taking ITV classes, enrolling only when necessary to obtain a particular course. The most commonly used seats in the classroom are those out of camera range, and students rarely speak during class. Anecdotally, Instructors dislike teaching these courses because they require a course conversion, adapting existing materials and methods to conform to a very restrictive format. Consequently, one would expect student learning to be non-optimal.

\section{Method}

The recent call of the CPE to increase engineering enrollment has led to an opportunity to begin a multi-institutional, cross-disciplinary effort to offer pre-engineering and engineering courses across the state, and at the same time update distance learning classrooms to accommodate the demands of individual courses. This has to be done within the constraints of stagnant (or potentially contracting) state education budgets and equipment limits of grant programs. The current plan, scheduled to be implemented beginning this summer, is to evolve the current distance learning classroom. The plan of modifying, or expanding, the current systems allows 
current offerings to continue without interruption and eliminates the costly requirement of establishing a new distance learning infrastructure.

The redesign of the classrooms has been driven by the needs of the Process Principles course, as well as a recognized need to reduce the reluctance of students and instructors to participate in distance classes. This requires that the instructor be freed from his cage and allowed to teach using the most effective techniques available. It also requires involving the student in the class, both in "passive mode" as a listener, and in active learning exercises. If implemented well, this should result in an improved learning experience for the student.

The critical emphasis in this redesign has been to seek ways that current technology can serve instructional goals. While videoconferencing technology has advanced in many forms, professors in the Paducah program seek to implement only those tools which enable "best practices" to be used during class. Facilitation of group work at remote sites has also been a key emphasis of the long-term redesign.

Simultaneous with the classroom modifications, preparations for offering Process Principles by distance have motivated development of a separate project. A software development project is underway to produce a framework and initial content to function as a learning-style-driven tutorial for the course. The software will adapt to student needs, so that students will not need to conform to a particular technology or software structure to benefit from use of the package. This project is the subject of a future paper.

Specific limitations of the ITV system will be addressed as follows:

- Limitation on number of outgoing video streams

The internet will be used to supplement the ITV system using standards-based video conferencing, remote desktop software, and other technologies. The primary video stream will remain on the ITV system.

- Instructor must remain behind control panel

- Instructor must produce the transmission

With simultaneous transmission of instructor video and a secondary source, such as a PowerPoint presentation, a digital whiteboard image, or a digital document camera image, the instructor will no longer need to do significant context switching or other production tasks. Switching between those aforementioned inputs will be accomplished by a dedicated keypad or remote control. Adding a tracking camera to follow the instructor across the front of the classroom will eliminate a requirement of keeping the instructor in a fixed location.

- Students are detached from the classroom due to similarities with watching TV 
The TV monitors will be replaced with LCD projectors to give a more immersive effect. Separate projectors will be required for the incoming ITV image and the high-resolution internet based transmission.

- Students cannot participate in group activities

Student stations will be equipped with computers capable of multipoint video conferencing coordinated by the instructor. Video, voice, chat, and data-sharing will be possible amongst students with instructor oversight and supervision.

Enabling group work is a critical aspect of this project, but also an expensive one. A new classroom at the UK-Paducah facilities is being outfitted with furniture appropriate for the design envisioned. Networked workstations will eventually be in place for each student, including a webcam, microphone, and digitizing tablet (to allow "natural" handwritten communication).

Attempted, at a minimum, therefore, is replication the $\mathrm{f} 2 \mathrm{f}$ classroom experience. This includes interactive use of a whiteboard, and enabling use of existing resources without conversion. Instructors will move around the classroom normally. Students will see a life-size image of the instructor, and a detailed view of class materials which will, by their nature, be digitally archivable and can be made available for later download.

Additional equipment is also planned for the classroom: a dedicated server for each classroom, managed remotely in cooperation with local site personnel; a digital document center, for transmission and reception of homework, assignments, and other materials; and a videoconferencing PC, to enable group efforts on homework and projects outside of class.

The overall project to extend pre-engineering and engineering classes across Kentucky also provides for "faculty associates," content proficient professionals who will assist in the course offerings at local sites. This provision offers significant potential improvement over "virtual" courses where limited interpersonal interaction may be available.

Training is a key concern of this project. While it should be easier to teach a distance course after this update than for the original ITV system, some training must be provided for instructors to maximize student learning. Students will also require an orientation to familiarize themselves with the enhanced system.

IV. Implementation

The current plan calls for modifying two existing classrooms, one in Paducah and one in Lexington, during Summer 2002, with the majority of the changeover occurring in Summer 
2003. The primary addition will be a digital whiteboard, either a stand-alone board (such as a SmartBoard by Smart Technologies ${ }^{4}$ ), or modifying an existing whiteboard with a device such as a Mimio ${ }^{5}$. A server at each will be required to coordinate transmission of images between sites. Minimal requirements for each server are expected to be an Intel ${ }^{6}$ Pentium 4 class machine, with 512 MB RAM, dual head video output, and a powered USB hub. A high resolution document camera $\left(\mathrm{ELMO}^{7}\right)$ will be added to replace the current analog document camera on the ITV system. A scan converter may be used to maintain compatibility with the ITV system for legacy use. Image transmission will be accomplished through a "remote access" software package, either by using SynchronEyes by Smart Technologies ${ }^{4}$, or by using remote desktop features of Microsoft ${ }^{8}$ Windows XP.

Additional classrooms will be outfitted based on the results of the initial deployment over the following two years. The first offering of Process Principles via this enhanced ITV system (eITV) is scheduled for Fall 2006. Equipment costs are expected to run about $\$ 35,000$ per site.

\section{Assessment}

It is key that students are indeed achieving the learning outcomes needed to succeed later in the engineering curriculum. The assessment methods practiced by the ABET-accredited UK CME Department (which includes BS-degree programs both in Lexington and Paducah) will be used as a baseline for assessment. Common exams and assignments will be offered to $\mathrm{f} 2 \mathrm{f}$ sections and distance sections of the course. Dr. Joan Mazur, Associate Professor of Education at UK, is assisting with implementing an evaluation plan to determine the efficacy of the pre-engineering and engineering distance course offerings.

\section{Further Development}

After the initial deployment and assessment of the upgrade to an eITV system, addition of group learning capabilities will be added to selected sites on the state distance learning network. The first step is placing networked computers at each student station, each outfitted with course appropriate software along with access to suitable conferencing software. IBM/Lotus LearningSpace ${ }^{9}$ appears especially suited to the intent of enabling in-class collaborative activities. Outside of class, Lotus ${ }^{9}$ Sametime or Microsoft ${ }^{8}$ MSN Messenger contain the fundamental communication tools required for groups of students to work on homework.

\section{Conclusions}

The redesign of a distance classroom has been developed, with due consideration for the instructor, the student, and the course content. The instructor will be freed to use natural teaching methods and current resources without conversion; the student will have a more immersive environment, and (by the end of the project) a truly interactive learning experience at 
least equivalent to a live class. The redesign consists of supplementing an existing transmission system with a parallel peer-to-peer data network using the internet for its low bandwidth transmissions. Additional hardware includes a host computer, a digital whiteboard, a digital document camera, and a tracking video camera. The enhanced classroom is expected to improve the quality of distance educational offerings in Kentucky, and, in particular, assist in increasing enrollment in engineering programs by providing opportunities at two-year institutions across Kentucky to better prepare for an engineering major, enroll in a four-year institution, and graduate two years later with a bachelor's degree in an engineering discipline of the student's choice.

Bibliography

1. Felder, R.M., Forrest, K.D., Baker-Ward, L., Dietz, E.J., and Mohr, P.H., "A Longitudinal Study of Engineering Student Performance and Retention. I. Success and Failure in the Introductory Course." J. Engr. Education, 82(1), 15-21 (1993).

2. Smart, J.L., Murphy, W., Lineberry, G.T., \& Lykins, B. Development of an Extended Campus Chemical Engineering Program. Proceedings of the 2000 ASEE Annual Conference \& Exposition. American Society for Engineering Education, (2000).

3. Capece, V.R., Murphy, W., Lineberry, G.T., \& Lykins, B. Development of an Extended Campus Mechanical Engineering Program. Proceedings of the 2000 ASEE Annual Conference \& Exposition. American Society for Engineering Education, (2000).

4. URL: http://www.smarttech.com; Smart Technologies, Inc.

5. URL: http://www.mimio.com; Virtual Ink Corporation.

6. URL: http://www.intel.com; Intel Corporation.

7. URL: http://www.elmo-corp.com/; ELMO.

8. URL: http://www.microsoft.com/; Microsoft Corporation.

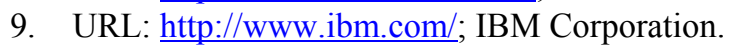

\section{DAVID L. SILVERSTEIN}

David L. Silverstein is currently an Assistant Professor of Chemical and Materials Engineering at the University of Kentucky, assigned to the College of Engineering Extended Campus Programs in Paducah. He received his B.S.Ch.E. from the University of Alabama in Tuscaloosa, Alabama, and his M.S. and Ph.D. in Chemical Engineering from Vanderbilt University in Nashville, Tennessee. He has over twenty years experience in microcomputer programming, most recently in development of a prototype automatic custom videotape editing and production device. In addition to teaching, Dr. Silverstein is developing a computer framework for applying teaching styles to a multimedia computer based supplement to engineering courses.

\section{G.T. LINEBERRY}

G.T. Lineberry is Associate Dean for Commonwealth and International Programs and Professor of Mining Engineering, University of Kentucky. Dr. Lineberry received his BS and MS degrees from Virginia Tech and his $\mathrm{PhD}$ degree from West Virginia University, all in Mining Engineering. He is author/coauthor of over 60 journal articles, conference proceedings, government reports, and book chapters, and was a section coordinator and contributor to the SME Mining Engineering Handbook (2nd ed). 